The role of high-risk occupations in the spread of AIDS: truck drivers and itinerant market women in Nigeria

I.O. Orubuloye, Pat Caldwell and John C. Caldwell

Health Transition Working Paper No. 10, 1992 


\section{The role of high-risk occupations in the spread of AIDS: truck drivers and itinerant market women in Nigeria}

\section{I.O. Orubuloye, Pat Caldwell and John C. Caldwell}

In sub-Saharan Africa, AIDS has spread along the roads, especially the major highways, and HIV incidence is often higher closer to these main roads. Both the general public and researchers have identified long-distance truck drivers and women working along the roads as playing a role in this phenomenon (Tierney, 1990). Both have been found to exhibit higher HIV levels than other persons living and working in the same district.

The danger of the roads and those who work them was not a theme when AIDS was first identified, but is now regarded as so obvious that little research has been done in this area. Yet, in Africa, with its contiguous countries and tens of thousands of miles of national and district land borders, the roads seem to present uninfected areas with their greatest threat from the epidemic. The focus of this study is whether that threat is merely a function of movement and the number of people moving or whether the roads form a sexual network which can be studied, understood and perhaps kept within safer bounds. We present evidence that the transport system has certain well defined characteristics that make it also an HIV infection system.

Most of the research on the incidence of HIV/AIDS along the roads pertains to the Zaire-Rwanda-Kampala (Uganda)-Nairobi-Mombasa (Kenya), route which forms a westeast axis from Middle Africa to the Indian Ocean and which traverses some of the earliestinfected and worst-infected parts of Africa. It forms the eastern segment of the route designated the Trans-African Highway from Dakar to Mombasa. Studies along this highway in Uganda have found among samples of long-distance truckers an HIV prevalence of 35 per cent, with 37 per cent of truckers estimating their number of different female sexual partners at over 50. The HIV-positive truckers were more likely than the others to have had a history of syphilis or genital ulcers (von Reyn, 1990) .

In East Africa, AMREF has obtained information on the highways as a preliminary step to organizing interventions. In Kenya, they concentrated on the Nairobi-Mombasa section of the West-East highway, and attempted to identify the women with whom the truckers had sexual relations (Nzyuko, 1991:10). As expected, they found that many of the women offering sex were full-time sex workers, but they also found competition from girls in fulltime education, seeking to maintain themselves and to pay their educational costs. Furthermore, the latter are increasingly getting a larger share of the market because the drivers are becoming more conscious of the danger of STDs and of HIV/AIDS, and believe that teenagers and those in their early twenties are less likely to be infected. Exactly the same conclusion has been drawn on the other side of Africa, also on the Trans-African Highway, but 3,000 road miles to the west, outside Benin City, at the great truck stop where the older and newer highways across southern Nigeria meet (F. Omorodion, personal communication). In Tanzania the AMREF highway research showed that the typical truck driver was married, in his early thirties, and had been in the job for over three years. In contrast his sexual partners at truck stops were typically single, in their early twenties, and, when employed, often as barmaids, had held their jobs for less than two years (Muizarubi et 
al., 1991:4). Typically, these relations occurred at large truck stops characterized by stalls, hawkers, bars, guest houses or hotels, and sometimes brothels.

In 1990 Nguma et al. held interviews with 159 drivers employed by five large Tanzanian trucking firms at their headquarters in Dar es Salaam in order to examine the drivers' awareness of AIDS and use of condoms (Nguma, Leshari and Mpangile, 1990). They found that the great majority of the drivers were in the age range $25-45$ years, 86 per cent were married, 95 per cent were literate, and 41 per cent had completed the full seven years of primary school while 61 per cent had completed four years. Each trip away from home averaged five weeks in duration, while 95 per cent regularly were away for at least five days. A part from their wives, most had semi-permanent partners at regular nightly stops, and, in addition, 75 per cent commonly enjoyed more casual sex at truck stops with barmaids, prostitutes and other women working there. Although nearly all have a good understanding of AIDS, very few usually employ condoms in casual sex. Significantly even those who do, fail to suggest it with their semi-permanent partners for the same reason that they do not suggest condom use to their wives, namely that this would imply that they regarded the relationship as a dangerous one. Yet this exposes drivers to the risk of infection from at least their semi-permanent partners, and exposes both these partners and their wives to infection from them.

The identification of major transport arteries as highways of both commerce and sexual activity, much of the latter also commercial, and consequently as strips of unusually high incidence of sexually transmitted disease which serve as sources of infection for the surrounding country, is not new. West Africa's old caravan routes were characterized by high levels of venereal diseases and lower fertility levels (David and Voas, 1981:644). The commercial penetration of Zaire at the time of the Congo Free State in the last two decades of the nineteenth century, admittedly an unusually violent form of commerce, resulted in such a rise in sexually transmitted disease and the level of infertility that the effects were still evident in the middle of this century (Caldwell and Caldwell, 1983). The history of Gabon, at least in terms of sexuality and sterility, has been similar (Balandier, 1970:190-200).

The transport nodes at which the drivers stop either temporarily or for the night are identified not only with transport and drivers but also with trade and hawkers, for road transport not only brings goods for sale but also carries many of the customers to and from the spot. Customarily, in Nigeria the lorry park and the market are adjacent. And they are by no means separate for retailing is undertaken not only from stalls but also by itinerant sales persons who carry their wares with them and invade the lorry park accosting both drivers and passengers. In Niger State, in Nigeria's Middle Belt, Nadel (1942) identified market women in the larger towns with commercial sexual services, but among the Yoruba in southwest Nigeria this has normally been denied (Nadel, 1942:152-153, 333-334; Sudarkasa, 1973:130-131). Yet those denials have usually most explicitly referred to the older established market women, usually with fixed stalls, and little attention has been paid to the younger itinerant female hawkers who are commercially more marginal but who have the strongest links with the transport system.

\section{The 1991 Nigerian Transport System Study}

Nigeria has long experienced significant levels of sexually transmitted disease: a decade ago it appeared that the prevalence of gonorrhoea in the general population could be as high as 10 per cent, while syphilis was half that level, and herpes was common. These levels were well above those in industrialized countries (Osoba, 1981). 
However, with regard to AIDS, HIV cases have been identified only in the last three years, and their number is still small. Nevertheless, this could be the beginning of a major AIDS epidemic, and researchers have begun to examine the mechanisms whereby the disease might continue to enter the country and how it might thereafter spread. The highest HIV-levels have, in terms of occupation, been reported among commercial sex workers, and, geographically, in the major nodes of transport and commerce: Lagos, Ibadan, Calabar, Enugu and Maiduguri (Shokunbi, 1991). The last three centres are significant, because, although far away from metropolises of the southwest, they are the cities most connected by transport links with the countries of Middle Africa where the AIDS epidemic. is at a more advanced stage. By 1991 HIV-positive truck drivers had been detected and there was beginning to be concern in the industry.

It was in this situation that the study of the Nigerian transport system was planned as part of a joint project of the Faculty of Social Science, Ondo State University, Nigeria and the Health Transition Centre, Australian National University, with collaborative inputs from the Nigerian Institute for Social and Economic Research, Ibadan, and the West African Research Group on Sexual Networking (see Acknowledgements).

The project aimed at understanding the transport and commercial networks and their relation to sexual activity and the threat of AIDS by carrying out three interrelated studies: (1) long-distance haulage drivers, (2) the itinerant female hawkers in lorry parks and truck and bus stops, and (3) the semi-permanent partners of truck drivers at night stops around the country. The latter proved to pose major problems in terms of both identification and logistics, and accordingly the research program concentrated in the second half of 1991 on studies (1) and (2), the findings of which are presented here. The program aimed not merely at measuring sexual activity but at understanding the internal logic of the systems that resulted in such activity. Both reported segments of the project were carried out in Ibadan, Nigeria's third city, a metropolis with around two million inhabitants, inland and to the north of Lagos. Ibadan is a major commercial and transport node, where roads divide and lead to much of the rest of the country.

\section{(1) Long-distance haulage drivers}

The colonial development of Nigeria's transport system was largely a product of the first half of the present century, partly because the full framework of the British possession, including the North, was only established in 1900. Accordingly, there was no development of a dense railroad system as occurred in India, and road transport has always been dominant. This dominance increased during the 1970s and early 1980s, as the oil boom allowed governments to build modern highways, firms to invest in large trucks, and the community to demand far more consumption goods.

A study made at the beginning of the 1980s of Nigerian long-distance haulage drivers confirmed that they spend much of their lives on the road (Ogunjemilua, 1982:258-297). Two other findings are also relevant for our study. The first is that drivers are relatively well-off, not so much because of their wages, but because they bend the regulations to earn extra money by agreeing to take additional goods for people who pay them directly. The second is that lorry or truck driving is a selective occupation which attracts adventurous men who are, more than most people, given to taking risks. This is what Nguma and his colleagues (1990:5) appear to have meant when they described the Tanzanian truck drivers as belonging to a unique subculture. 
The following analysis is drawn from both a survey of drivers and in-depth interviews, as well as from general knowledge of the industry.

Nigerian drivers stop for the night in places where they are permitted to do so, usually where the road widens or they can pull over. Buildings and shacks, which serve as eating places and bars, as well as places to spend the night and find sexual partners, develop at these places. Young female hawkers attempt to sell their goods and often, but more discreetly, their sexual services, to drivers and passengers.

Near these stops are houses and shanties where women live, quite frequently with husbands and children. It is here that drivers often pass the night. Drivers who ply the same route for long periods crave home comforts: home-cooked food, familiar surroundings, a bed they can call their own, and female friendship and accompanying sex, rather than anonymous entertainment and commercial sex. This may be partly because they fear the consequences of commercial sex, but it is largely because they fear the loneliness and expense. If they cannot have a single permanent home, then they will have a semi-permanent home at every stop where they will be welcomed and looked after. It provides them with a much more integrated life than they would otherwise have, and, even if they make considerable outlays, it is cheaper than any other form of board and accommodation. Furthermore, the expenditure is an investment in friendship for women they have usually long known and will continue to have as partners.

In a sense, the drivers have a wife in every town, or at least every night stop. They achieve this by keeping to the same route and employing the same stops for years at a time. In a polygynous society, the drivers enjoy the approximation to polygyny on the old chiefly scale that is now part of history. Most of the drivers of the larger vehicles are important and well-paid men and easily fill the role of a chiefly polygynist. Some are actually married to wives at various stops or destinations and this partly explains why they have atypically high levels even of formal polygyny.

Some of their overnight consorts also work between visits in the bars and some of the accommodation for drivers is at the back of bars. The distinction between these drivers' sexual partners and the sellers of more anonymous commercial sex is slight, and hence, in terms of the risk of infection, dangerous. Some women live in families which depend on the additional infusions of income from one or more drivers. When the women are companions to more than one driver, there is always a possibility of driving schedules changing and of two drivers turning up on the same night, often with the result of quarrels and fighting.

On Ibadan's Ring Road, near the junction to the highway north to Ilorin and beyond, there is a night stop for long haulage drivers that is large even by Nigerian standards. There are masses of huge trucks for half a mile. There is a great deal of noise and movement, and engines, oil and tyres are changed. Mechanics and hawkers are everywhere. In June 1991 the research program interviewed over three days the 243 long-distance haulage drivers who stopped there. The drivers were busy, rather self-important, and did not give up their time easily. In fact most only tolerated interviews from cheerful, attractive, interestingly $\mathrm{d}$ ressed young women, and it was these members of the research team who increasingly bore the load of the interviewing. Some of the drivers probably hoped for a continuing relationship, and few refused the interview.

The drivers ranged in age between 20 years, the lowest age at which the appropriate $E$ class driver's licence can be obtained, and 60 years, the highest age at which most firms will 
employ drivers. Their average age was 36 years, and five-sixths of them were between 25 and 45. Most had started driving at between 20 and 25, and had on average been drivers for 14 years. Their vehicles were usually large, 56 per cent being articulated trailers and semitrailers and a further 11 per cent tankers. The latter predominantly carried petrol, but the former transported a great range of goods from food to building materials. In addition, the drivers supplement their incomes by picking up passengers and charging them for the trip, and by carrying additional goods that are usually small in size and of some value.

Partly because the trucks were going to the north, and partly because of a long tradition of male commerce, caravans and other forms of nomadism in the north, 58 per cent of the drivers were Hausa. Most of the rest of the drivers were Yoruba, but even they were almost three-quarters Muslim in religion, well above the Yoruba average, apparently because Muslims felt more comfortable in the north. There were also some Igbos, a people who have long traded with the north.

These drivers are well off. Their stated incomes averaged 15,000 Naira (US\$1,500) per year, well above other non-white-collar incomes. They earned these incomes in spite of low education levels. Only 11 per cent had any education beyond primary school, while a further 46 per cent had at least some primary schooling and 43 per cent had no schooling at all. These factors combined to yield a high level of marriage and an even higher one of polygyny. Only 20 per cent were single while 79 per cent were currently married. Of the latter, half had polygynous marriages and over three-quarters of their wives were in polygynous marriages. This can be compared with a figure for the country as a whole of about 45 per cent of currently married women being in polygynous marriages. The high level of polygyny helps to explain why men averaging 36 years of age reported an average of 5.2 children.

The pattern of their occupational life explains their sexual networking. Most of the drivers reported travelling the same routes for years past. Most habitually break their journeys at the same stopping places. The average period spent away from home on each journey is nine days and eight nights.

Although 5 per cent of the drivers reported having no current sexual partners beyond their wives, these were mostly drivers on the shorter runs. The drivers as a whole reported an average number of 6.3 current sexual partners, and the number reported by most of them was the same as the number of different locations where they spend the night (many spend two nights at their final destinations before turning around). This receives additional confirmation from the fact that 70 per cent of the drivers report that they never have more than one woman with whom they are currently sleeping at each stop.

Drivers live in this cultural atmosphere of extensive de facto polygyny and drivers who do not live this way feel that they are hardly part of the crowd. Over the previous month, drivers reported only 5.3 different sexual partners beyond their wives. This was one partner less than the number reported as 'current' partners, but this is explained by the irregularity of some trips. Other research on more sedentary populations has also reported current figures being lower than those for a month (Orubuloye, Caldwell and Caldwell, 1991), and clearly 'current' is taken to refer to partners with whom there is continuing understanding and to whom there is sexual access. However, truck routes change and drivers fall out with their female companions. Beyond their wives, drivers had averaged over the previous year 11.9 different sexual partners and over a lifetime 25.3. This means that the truck stop women are forced to move on from one driver to the next, which increases the chance of 
sexually transmitted infection. In countries where there is a substantial level of AIDS, the sickness or death of a driver can be a prime reason for this move.

But each driver turns up at a specific stopping place only rarely, as little as once a fortnight. This means that the contribution to the woman and her household for a single night's accommodation and entertainment can hardly carry them through until the next visit. Inevitably, apart from husbands, most have other boy-friends, usually drivers. We asked the drivers if they knew who their partners' other partners were. Only 36 per cent believed that they knew all about any other partners, and these may well have been relationships which had a lower level of sexual networking than others. This group reported believing that there were on average three other partners (the median number is two). Half of the identified other partners were drivers.

Clearly, in terms of the risk of transmission of coitally related disease, this is a fairly explosive situation. Nearly all the drivers knew of sexually transmitted diseases, although most could only identify gonorrhoea, which is apparently the most common STD in Nigeria (Osoba, 1981). Four-ninths of them reported having been treated for STDs, 72 per cent of this group for gonorrhoea, 20 per cent for syphilis, and 8 per cent for both. One-third knew that one of their sexual partners had suffered from an STD. What is more surprising is the nature of treatment, because only 51 per cent had gone to a modern doctor or hospital, while 14 per cent had sought treatment from chemists and 35 per cent from traditional healers. The latter figure is partly explained by their low educational levels and partly by the fact that diseases of the reproductive organs are thought to be more the speciality of traditional medicine than is any other kind of disease.

The greatest threat posed by the sexual culture of the transport industry comes from HIV/AIDS. Nearly all drivers have heard of the disease and appreciate the risk it might pose. One in ten claims to have known a person with the disease, almost twice as many males as females being cited. This seems improbable in view of the low level of the epidemic as yet in Nigeria, but the disease is likely to show up early along the main transport arteries, and a single case among the drivers or their women companions would soon become known to large numbers of drivers. Only a minority of the infected persons were said to have sought modern medical help and a majority were reported as having died. Few employ condoms and hardly any on a regular basis. To do so with their wives would imply either an admission of irresponsible sexual activity during their journeys, or a lack of trust in their wives during these absences. The wives guess what goes on when their husbands are on the road and they too, prefer the more permanent relationships to the casual commercial encounters. The latter are seen as more likely to result in infection and probably as more expensive. Most wives apparently would prefer their driver husbands to have their more permanent relations with married women, because there is then less chance that they will expand their existing families by further polygynous marriages. Most wives make little fuss about what their husbands do elsewhere, partly because Nigerian culture dictates that they should behave in this way (P. Caldwell and J.C. Caldwell, 1981:88) and partly because well-off drivers are valuable husbands.

In one sense there is a single transport-sexual network which might prove to be very difficult to dismantle. It is efficient in that it helps to keep the labour force of drivers reasonably content and it reduces their living (and possibly sexual) costs so keeping down transport costs. It is also a major support for the communities along the road, and for communities back from the road which send residents, especially young women, to the road 
seeking employment and incomes. In fact, the coming into existence of accommodation, housing, eating places and populations along the highway makes it easier to provide other needed roadside services such as mechanics' workshops and merchants' stores from which goods are sold to the hinterland.

(2) Itinerant female hawkers

Female hawkers, selling a few items from a portable tray most frequently balanced on the head, a fly-proof box with glass sides and wooden angles, or a temporarily erected stand, are a feature of southern Nigerian life. They neither need the capital of the larger traders in the market nor receive the returns. In the past, unmarried girls usually assisted their mothers in trading, but an increasing number are now selling on their own in the lorry parks or at the pick-up stops along the road. Most of these girls hope to have a stall in the market some day, perhaps capitalized by a future husband. The lorry parks are typically beside the market and are fairly tough places. Young girls who trade there are often regarded as being, in a sexual sense, fair game for drivers or passengers.

In the research project the hawkers were interviewed in the lorry parks, and at the roadside stopping places in Ibadan. The research was carried out in June and July 1991 and 467 interviews were recorded. All located female hawkers were interviewed in each place and were identified in records so as to prevent accidental re-interviews.

As expected, the hawkers were young. Their ages ranged from 10 to 40 years, but the average age was only 19.7 years and three-quarters were bunched in the narrow range of 1522 years. They were fairly typical of the Ibadan poor. Ethnically, 87 per cent were Yoruba and most of the rest Igbos. Their education was lower than the city average for this age group, 14 per cent having no schooling and a further 43 per cent some schooling but not beyond the primary school level. The religious breakdown was similar to that of Ibadan as a whole, 54 per cent being Muslim and 43 per cent Christian.

Because of their young age, and a rising age at first marriage in the society, 71 per cent of them had not yet married, 27 per cent were married, half in monogamous marriages and half in polygynous ones, while 2 per cent were separated or divorced. Only 28 per cent had any children and this group largely coincided with those already married. Of those married, three-quarters had control of their own income but were largely responsible for supporting themselves and their children. Only a little over one-third normally ate with their husbands, but this probably does not vary greatly from the situation in the broader society of southwest Nigeria (Orubuloye, Cald well and Caldwell, 1992).

The respondents' period as hawkers ranged up to 20 years, but the median duration was under four years and most started not long after they left school. Most expected to give up when they married, many assuming that they would be staked by their husbands in a fixed or market stall. The great majority retailed only single items, of which the most common were bread, cosmetics, cooked food, fish, ice water, mineral drinks and plantains (the large unsweet cooking banana). Some sold other things ranging over 130 items from chewing gum to coconuts and from sugar to kola nuts. Typically, they were forced to sell their goods for little more than they had paid for purchasing them in the market. The median figure for their annual net earnings was only around 500 Naira (US\$50). A minority, mostly older, achieved greater returns as is shown by the fact that 20 per cent earned annually over 3,500 (US\$35). The lorry parks and roadside stops are, then, filled with young girls continually hopefully approaching prospective customers and earning very little income from retailing. 
Most of the women were not sexually inexperienced and only five per cent had never had sexual relations, approximately the same number who were under 15 years of age. About one-seventh had their first sexual relations with their husbands, and a further oneseventh with fiancees or anticipated future husbands. But most started sex with boy friends or older men and 15 per cent reported that they lost their virginity through rape. Their median age at the onset of sexual activity was 14 years, probably two to three years younger than is typical of the society, but significant numbers began sexual activity from 10 years of age onward. In their first sexual encounter, almost half claim that some method was adopted before or after the act to attempt to prevent conception. However, only one-third of these attempts employed any contraceptive method that was likely to prove effective, most frequently the condom. The other supposed contraceptives cover a great range, but the most common are mineral drinks, which, especially if bitter, were drunk and were employed more often than oral contraceptives, and juices from various citrus fruits.

By this time most of them are more sexually experienced and 62 per cent claim to be practising contraception. At the time of the survey, 38 per cent were confining themselves to a single sexual partner, while 26 per cent had two partners and 33 per cent three or more. Over their rather short lifetimes, 29 per cent had had six or more sexual partners and 8 per cent 10 or more.

The study had been first planned because it was noticed that drivers, passengers and other men frequently made passes at these young women. Four-fifths of the respondents said that such passes were frequently made and two-thirds that men in making the passes attempted to stimulate what they called their 'private parts'. Half of them said that, as a result, they were sometimes cajoled into sex by men other than their boy-friends or husbands and 45 per cent said that this happened frequently. Thus, for about half the young hawkers their sales income appears to be supplemented by income from sexual activities. Around 60 per cent claim to know these men well enough to be able to identify their other partners, but this probably means their regular partners and not, for instance, encounters with other itinerant hawkers. Nevertheless, there is evidence here that most of the relationships are not anonymous and this may suggest that the number of sexual contacts is not indefinitely large.

The young female itinerant hawkers add a great deal to the efficiency of the Nigerian transport system and to the Nigerian way of life. An amazing range of goods is retailed to the windows of buses and trucks as soon as they slow down at a stopping place. The competition is tremendous and the earnings almost derisory. Many of these girls receive very little support from their families and hence are dependent on retailing goods, and, necessarily, often sex. Their chance of a sale depends on offering friendship and goodnatured banter, and often on long acquaintance with drivers or frequent passengers. They offer a fresh alternative to semi-permanent and near-spousal relationships. Furthermore, as the AIDS message is more frequently heard, many drivers and other males tend to see in the girls' youth the fact that they are not full-time commercial sex workers, and, indeed, that many of them have had little sexual experience, thus providing a protection against the dạnger of HIV infection.

The young women are increasingly worried about the relationship between sexual relations with a range of people and risks to their health. Over one-fifth reported having had an STD, mostly gonorrhoea. They now have some concern about AIDS and 92 per cent have heard about it. How the young women have learnt about AIDS is very instructive. In Nigeria 
it is as yet a disease to be feared, mostly on the basis of the experience of other countries, rather than an epidemic with which most people have had personal contact. What is known has been learnt largely through the activities of the Federal Ministry of Health and it says much for those activities that the great majority of these young women had heard and understood the message. These messages were essentially government ones and only 11 per cent of all messages had been heard from friends and 7 per cent from the market. In contrast, 40 per cent of the information had come from the radio and 33 per cent from television, testimony to the spread of the electronic media in Ibadan. A further 7 per cent of the messages had been heard at school and only 2 per cent from health centres. Apparently, not even treatment for STDs normally warrants a warning about AIDS. A surprisingly low level of information originated with the newspapers.

\section{Transport and trading as commercial and sexual systems}

An examination of long distance haulage drivers shows that the relationship between highways and the spread of HIV/AIDS is by no means fortuitous or largely the result of the number of people moving and the fact that many of them come long distances. Rather it is a reflection of the way of life on the highways and especially that of the professional drivers and of the women at the roadside stops who cater to their needs. This will not be changed easily, even by a major HIV/AIDS epidemic. The drivers do not dally with these women for an incremental bit of fun. It is part of their whole way of life and, in a poor society where motels and restaurants cannot easily be afforded, of their accommodation and feeding arrangements. More importantly still, in a polygynous society, it provides men who would be lonely on the roads for most of their lives with extensive de facto polygynous families and hence with a home life, and even a family life, which extends the length of their routes and across the country. It probably does much to keep the transport system going.

The roadside bars and small hotels are the complementary side of the system and of the health risk. Their earnings bring money not only to their owners and to the women who work there, but to whole families and districts in lonely and often poor and unproductive parts of the country. In addition, in the nodal towns and cities along the routes in southern Nigeria, the female itinerant traders add to the risk to the drivers and passengers and provide a channel through which those connected with the transport system can pass on infection to more sedentary populations. One should not underestimate the contribution to both the national economy and to the available services of both drivers and hawkers. But they may yet play a role in spreading the most dangerous epidemic the world has ever known.

The whole transport-commercial-sexual system is deeply rooted in the nature of the society itself. Polygyny levels are still high in Nigeria (almost half of all married women are currently in a polygynous union and a much higher proportion will be in the course of their lives), and most men, especially from the social classes from which the drivers are drawn, take multiple sexual relationships for granted. Indeed, some of the women involved in semi-permanent relations with the drivers do eventually marry them and more bear their children. What makes the whole system dangerous in an era of AIDS is that this attitude toward multiple relations, together with the drivers' ebullient attitude toward life, the fact that their routes and stopping places sometimes change, and their relative affluence, means that most of them continue to have occasional commercial sex, rarely protected by condoms. Many continue to suffer from STDs because they seek inappropriate treatment, and the same pattern of behaviour may well persist with AIDS. 
In southwest Nigeria, where Ibadan is located, most women work, often from very early ages, and the young itinerant hawkers from the poorer strata of society probably largely have to support themselves. Certainly, for any new clothes, shoes or ornaments, possessions which they value, this is true. The society is not obsessed with premarital virginity, and it is largely taken for granted adolescent girls will be sexually active (Nichols et al., 1986; Orubuloye et al., 1991:70). In addition, much of sexual relations has a transactional element (Caldwell, Caldwell and Quiggin, 1989:203-205; Orubuloye et al., 1991:70), and where support or survival is involved, a woman would often be regarded as foolish not to offer or accept sexual relations, and as irresponsible not to accept assistance in return. For some, there is a real thrill in being with one of the kings of the road, the captains of huge, expensive vehicles that dominate the highways.

The existing system provides an efficient and cheap transport and commercial network throughout the country. It also supports large numbers of people, and diffuses money among the poor of the city and from the highway into vast, poor rural areas where living standards are low and the roadside stops constitute one of the few ways of tapping into the modern world economy. The system has doubtless sustained the older sexually transmitted diseases at higher levels than would otherwise have been the case, and threatens to be an explosive mechanism for the spread of AIDS. IT is a more highly developed system with a greater density of trucks, markets and hawkers than is probably found anywhere else in subSaharan Africa, and it meets the needs of well over 100 million people or almost one-quarter of the inhabitants of sub-Saharan Africa. It will prove difficult to modify even in terms of rendering its sexual relations safer. Nevertheless, STOPAIDS campaigns have already begun at some of the country's largest lorry parks (Stearns, 1991).

\section{Acknowledgements}

This research has been supported by the Rockefeller Foundation, the Swedish Agency for Research Cooperation with Developing Countries (SAREC), The Australian National University and Ondo State University. The authors wish to acknowledge the coordinating and supervisory role played by Dr. Olu Moloye, Nigerian Institute for Social and Economic Research (NISER), Ibadan, in the study of itinerant female hawkers, and the assistance provided in Nigeria by Hope Christopher, Gloria Eze, Titilayo Oyekan, Seyi Fijabi and Bunmi Omogboye, and in Australia by Ben Amenuvegbe, Jennifer Braid, Wendy Cosford, Angela Naumann and Pat Goodall.

\section{References}

Balandier, G., 1970, The Sociology of Black Africa: Social Dynamics in Central Africa, Andre Deutsch, London (Tr. D. Garman; first publ. in French, 1955).

Caldwell, J.C. and Caldwell, P., 1983, 'The demographic evidence for the incidence and cause of abnormally low fertility in Tropical Africa', World Health Statistics Quarterly, 36,1:1-33.

Caldwell, J.C., Caldwell, P. and Quiggin, P., 1989, 'The social context of AIDS in Sub-Saharan Africa', Population and Development Review, 15,2:185-234.

Caldwell, P. and Caldwell, J.C., 1981, 'The function of child-spacing in traditional socities and the direction of change', in H.J. Page and R. Lesthaeghe, eds, Child-Spacing in Tropical Africa: Traditions and Change, Academic Press, London, pp.73-92.

David, N. and Voas, D., 1981, 'Societal causes of infertility and population decline among the settled Fulani of North Cameroon', Man, N.S.16:644-664. 
Muizarubi, B., Cole, L., Outwater, A. and Lamson, N., 1991, 'Targeting truckers in Tanzania', AIDS and Society, April/May:4.

Nadel, S.F., 1942, A Black Byzantium: The Kingdom of Nupe in Nigeria, Oxford University Press, London.

Nguma, J.K., Leshari, M.T. and Mpangile, G.S., 1990, Implications of cultural lag in the use of condoms for prevention of HIV infection among truck drivers in Dar es Salaam, Paper presented at the IUSSP Seminar on Anthropological Studies Relevant to the Sexual Transmission of HIV, Sonderborg, Denmark, 19-22 November.

Nichols, D., Ladipo, O.A., Paxman, J.M. and Otolorin, E.O., 1986, 'Sexual behavior, contraceptive practice, and reproductive health among Nigerian adolescents', Studies in Family Planning, 17,2:100-106.

Nzyuko, S., 1991, 'Teenagers along the Trans-African Highway', AIDS and Society, July/August:10.

Ogunjemilua, S.O., 1982, Long distance heavy road haulage transport in Nigeria: a case study of Maiduguri in Bornu State, unpublished Ph.D. thesis, University of London, London.

Orubuloye, 1.O., Caldwell, J.C. and Caldwell, P., 1991, 'Sexual networking in the Ekiti District of Nigeria', Studies in Family Planning, 22,2:61-73.

Orubuloye, I.O., Caldwell, J.C. and Caldwell, P., 1992, Focus and diffusion: sexual networking and identifying partners' partners, Manuscript, Health Transition Centre, Australian National University, Canberra.

Osoba, A.O., 1981, 'Sexually transmitted diseases in Tropical Africa: a review of the present situation', British Joumal of Venereal Diseases, 57,2:89-92.

Shokunbi, W.A., 1991, Paper presented to Meeting of the West African Research Group on Sexual Networking, STDs and AIDS/HIV, Nigerian Institute for Social and Economic Research, Ibadan, 17-19 November.

Stearns, S., 1991, 'Nigeria: living with a killer disease - war against AIDS', West Africa, 3867:1766.

Sudarkasa, N., 1973, Where Women Work: A Study of Yoruba Women in the Market Place and in the Home, University of Michigan Press, Ann Arbor.

Tierney, J., 1990, 'AIDS in Africa: experts study role of promiscuous sex in the epidemics', New York Times, October 19:A10.

Von Reyn, C.F., 1990, 'Epidemiology of HIV infection in Africa', AIDS and Society, April:3,8. 


\section{HEALTH TRANSITION CENTRE PUBLICATIONS}

\section{WORKING PAPERS}

1. Larson, Ann (1989)

Social context of human immunodeficiency virus transmission in Africa: historical and cultural bases of east and central African sexual relations

Review of Infectious Diseases, II, 5:716-731

2 Caldwell, John C., Pat Caldwell and Pat Quiggin (1989)

The social context of AIDS in sub-Saharan Africa

Population and Development Review, 15, 2:185-234

3. Orubuloye, I.O., John C. Caldwell and Pat Caldwell (1991)

Sexual networking in the Ekiti District of Nigeria

Studies in Family Planning 22,2:61-73

4. Caldwell, John C., I.O. Orubuloye and Pat Caldwell (1991)

The destabilization of the traditional Yoruba sexual system

Population and Development Review, 17,2:229-262

5. Caldwell, John C., Pat Caldwell and I.O. Orubuloye (1990)

The family and sexual networking in sub-Saharan Africa:

historic regional differences and present day implications.

6. Caldwell, Pat (1990)

Research Priorities: Behavioural Research

(with an Annexe on needed research with

priority suggestions)

6a. Caldwell, Pat (1990)

Annexe to Research Priorities: Behavioural Research

7. Caldwell, Pat and John C. Cald well (1990)

Gender implications for survival in South Asia

8. Orubuloye, I.O., John C. Caldwell and Pat Caldwell (1991)

The impact of family and budget structure on health treatment in Nigeria

9. Caldwell, John C., I.O. Orubuloye and Pat Caldwell (1991)

Underreaction to AIDS in Sub-Saharan Africa

10. Orubuloye, I.O., Pat Caldwell and John C. Caldwell (1992)

The role of high-risk occupations in the spread of AIDS: truckdrivers and itinerant market women in Nigeria 


\section{HEALTH TRANSITION SERIES}

1. Caldwell, John C. and Gigi Santow (eds) (1989).

Selected Readings in the Cultural, Social and Behavioural Determinants of Héalth.

Canberra: Health Transition Centre, Australian National University. xix $+305 p p$

2 Caldwell, John C., Sally Findley, Pat Caldwell, Gigi Santow,

Wendy Cosford, Jennifer Braid and Daphne Broers-Freeman (eds) (1990), What we know about Health Transition: the cultural, social and behavioural determinants of health, Canberra: Health Transition Centre, Australian National University xix + 933pp.

3. Cleland, John and Allan G. Hill (eds) (1991)

The Health Transition: Methods and Measures, Canberra: Health Transition Centre, Australian National University.

\section{JOURNAL}

Health Transition Review Vol. 1 No. 1 April, 1991

Health Transition Review Vol. 1 No. 2 October, 1991 